\title{
Exigência nutricional de lisina digestível para galinhas poedeiras no período de 34 a 50 semanas de idade ${ }^{1}$
}

\section{Luciano Moraes Sá ${ }^{2}$, Paulo Cezar Gomes ${ }^{3}$, Horacio Santiago Rostagno ${ }^{3}$, Luiz Fernando Teixeira Albino ${ }^{3}$, Priscila D'Agostini ${ }^{4}$}

\author{
1 Parte da tese de Doutorado do primeiro autor apresentada à UFV. \\ 2 Departamento Técnico - Poli-Nutri Alimentos Ltda. \\ ${ }^{3}$ Departamento de Zootecnia - Universidade Federal de Viçosa, CEP: 35671-000, Viçosa - MG. \\ 4 Doutora em Zootecnia.
}

RESUMO - Com o objetivo de estabelecer a exigência nutricional em lisina para galinhas poedeiras leves e semipesadas, no período de 34 a 50 semanas de idade, 360 poedeiras (metade Lohmann e metade poedeiras Lohmann Brown) foram submetidas

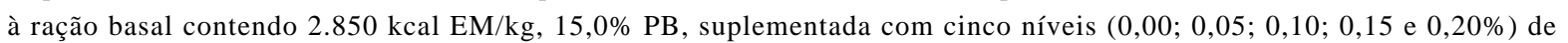
L-lisina, de modo a proporcionar 0,$584 ; 0,634 ; 0,684 ; 0,734$ e $0,784 \%$ de lisina digestível nas rações. Foi utilizado esquema fatorial 5 x 2 (nível de lisina e linhagem de aves), com seis repetições por tratamento e seis aves por unidade experimental, em um delineamento inteiramente casualizado. Foram avaliados a produção de ovos (\%), a massa e o peso médio dos ovos (g), o consumo de ração (g/ave.dia), a conversão alimentar (kg ração/dúzia ovos), a mudança de peso corporal (g) e a qualidade interna dos ovos (unidade Haugh e índice de albúmen e gema). Os níveis de lisina não influenciaram a mudança de peso corporal, o consumo de ração e a qualidade interna dos ovos em ambas as linhagens. A conversão alimentar e a produção de ovos, o peso médio e a massa dos ovos foram influenciados positivamente pelos níveis de lisina, em poedeiras leves e semipesadas. A exigência em lisina digestível, estimada pelo modelo quadrático, para as aves leves e semipesadas, foi de 0,732 e $0,715 \%$ na ração, que corresponde ao consumo diário por ave de 893 e $804 \mathrm{mg}$ lisina/ave.dia, respectivamente.

Palavras-chave: aminoácido digestível, aves, postura, proteína ideal

\section{Nutritional requirement of lysine for laying hens in the period from $\mathbf{3 4}$ to 50 weeks old}

\begin{abstract}
With the objective to establish the nutritional requirement of lysine for light and semi-heavy laying hens, in the period from 34 to 50 weeks old, 360 laying hens (half Lohmann and half Lohmann Brown) were submitted to a basal ration containing $2.850 \mathrm{kcal} \mathrm{ME} / \mathrm{kg}, 15.0 \% \mathrm{CP}$, supplemented with five levels $(0.00,0.05,0.10,0.15$ and $0.20 \%)$ of L-lysine, to provide $0.584,0.634,0.684,0.734$, and $0.784 \%$ of digestible lysine in the rations. A $5 \times 2$ (lysine level and laying hen strain) factorial arrangement, with six replications per treatment and six hens per experimental unit in a completely randomized design was used. Egg production (\%), egg mass and average egg weight (g), feed intake ( $\mathrm{g} / \mathrm{hen}$.day), feed conversion ( $\mathrm{kg}$ feed /egg dozen), body weight change $(\mathrm{g})$ and internal egg quality (Haugh unit, albumen and yolk index) were evaluated. The lysine levels did not affect the body weight change, feed intake and egg quality in both laying hen strains. Feed conversion and egg production, average egg weight and egg mass were positive influenced by the lysine level, in light and the semi-heavy. The digestible lysine requirement estimated by quadratic model, for the light and the semi-heavy laying hens, was 0.732 and $0.715 \%$ in the ration, corresponding to the daily intake per hen of 893 and $804 \mathrm{mg}$ lysine/day, respectively.
\end{abstract}

Key Words: digestible amino acid, ideal protein, layer, poultry

\section{Introdução}

As estimativas das exigências de aminoácidos para aves de postura são afetadas por uma complexidade de fatores que podem agir individualmente ou em conjunto. Os requerimentos diários de aminoácidos para as poedeiras são influenciados primeiramente pela massa do ovo, por outro lado, menor porcentagem das neces- sidades diárias é utilizada para mantença (Coon \& Zhang, 1999). Existem vários os fatores que podem influenciar os coeficientes de digestibilidade dos aminoácidos: metodologia experimental utilizada, níveis de consumo de alimento, concentração de proteína na dieta, presença de fatores antinutricionais, altas temperaturas e tempo de permanência das excretas nas bandejas coletoras. 
Os nutricionistas determinaram proporções ideais de aminoácidos essenciais em relação à lisina como base para o cálculo das especificações dos aminoácidos nas rações. A proteína ideal é definida como o balanço exato de aminoácidos essenciais e o suprimento adequado de aminoácidos não-essenciais, capazes de prover, sem deficiências ou excessos, as necessidades absolutas de todos os aminoácidos requeridos para manutenção e aumento da proteína corporal, utilizando-se a menor quantidade possível de aminoácidos como fonte energética (Schutte \& Jong, 2004). Uma vez que o requerimento de lisina esteja estabelecido, as exigências de outros aminoácidos podem ser facilmente calculadas (Chung \& Baker, 1992). A utilização da lisina como aminoácidoreferência deve-se à simplicidade de sua determinação analítica e ao uso exclusivo na síntese de proteínas, ao passo que alguns aminoácidos podem ser empregados com outros propósitos metabólicos.

Hsu et al. (1998) afirmaram que é possível otimizar a proporção de proteína bruta na ração e a produção de massa de ovos, visando à diminuição da excreção de nitrogênio para o meio ambiente, sem prejudicar o desempenho produtivo das aves. Rizzo et al. (2004) relataram que as poedeiras aproveitam mais eficientemente o nitrogênio da dieta e excretam menos nitrogênio para o meio ambiente quando alimentadas com dietas contendo níveis mais baixos de $\mathrm{PB}$ suplementada com lisina.

Objetivou-se com este trabalho estabelecer a exigência em lisina digestível para galinhas poedeiras em produção, no período de 34 a 50 semanas de idade.

\section{Material e Métodos}

Este experimento foi realizado nas instalações da Seção de Avicultura, do Departamento de Zootecnia da Universidade Federal de Viçosa-MG, no período de julho a dezembro de 2003.

Foram utilizadas 360 aves, 180 da linhagem Lohmann White LSL e 180 da linhagem Lohmann Brown, na fase de 34 a 50 semanas de idade. Antes do início do período experimental, efetuou-se a uniformização das aves nos tratamentos, padronizando-as por peso corporal e produção de ovos.

O programa de luz adotado durante o período experimental consistiu de 16 horas de luz e 8 horas de escuro. A temperatura do galpão foi monitorada, três vezes ao dia, por quatro termômetros de máxima e mínima, distribuídos por todo o galpão e posicionados à altura das aves.

Adotou-se delineamento experimental inteiramente casualizado, em esquema fatorial 5 × 2 -cinco níveis de lisina digestível e duas linhagens de aves (leves e semipesadas) - com seis repetições por tratamento e seis por unidade experimental. $\mathrm{O}$ experimento foi dividido em quatro períodos de 28 dias para coleta de dados.

A partir da $34^{\mathrm{a}}$ semana de idade, as poedeiras foram submetidas aos tratamentos, iniciando-se o período experimental, que teve duração de 16 semanas. As rações foram fornecidas, diariamente, em dois horários (7 e 17 h), garantindo às aves consumo de alimento e água à vontade, durante todo o período experimental (Tabela 1).

Para determinação da exigência em lisina digestível, foram formuladas dietas isocalóricas variando em cinco níveis de lisina, que foram obtidos a partir da dieta basal suplementada com 0,$00 ; 0,065 ; 0,130 ; 0,194$ e $0,259 \%$ de L-lisina, de modo a proporcionar 0,$584 ; 0,634 ; 0,684 ; 0,734$ e $0,784 \%$ de lisina digestível nas rações experimentais.

As suplementações com L-lisina foram feitas em substituição ao amido, a fim de assegurar que todas as rações permanecessem isocalóricas. As rações foram suplementadas, quando necessário, com metionina, treonina, triptofano, isoleucina e valina.

Para obtenção do nível deficiente de lisina na dieta basal, os teores de EM e PB foram inferiores e os dos aminoácidos essenciais, superiores às recomendações de Rostagno et al. (2000), de forma a atender as relações ideais de lisina em teste. Os demais nutrientes contidos nas rações foram balanceados de acordo com as recomendações de Rostagno et al. (2000).

Neste ensaio foram avaliados os seguintes parâmetros:

Produção de ovos: computada diariamente (duas coletas diárias realizadas às 11 e $16 \mathrm{~h}$ ). De acordo com o número de aves alojadas por unidade experimental, foram calculadas a produção média de ovos por ave alojada e a produção de ovos por ave/dia;

Consumo de ração: determinado ao término de cada período de 28 dias por meio da divisão da quantidade de ração consumida em cada unidade experimental pelo número de aves das unidades experimentais por dia. Dessa forma, o consumo foi expresso em $\mathrm{g}$ de ração por ave/dia. $\mathrm{Na}$ ocorrência de mortalidade na unidade experimental, foi descontado o consumo médio de cada ave morta para obtenção do consumo médio corrigido;

Conversão alimentar: calculada pela divisão do consumo de ração pela produção em dúzias de ovos $(\mathrm{kg} / \mathrm{dz})$ em cada período avaliado;

Peso médio dos ovos: foram utilizados todos os ovos íntegros coletados nos três últimos dias de cada um dos quatro períodos de 28 dias. A média do peso dos ovos foi obtida pela divisão do peso total dos ovos coletados pelo número de ovos coletados, por unidade experimental; 
Tabela 1 - Composições centesimal e calculada das rações experimentais (\%MS)

Table 1 - Percentage and calculated compositions of the experimental diets (\%DM)

\begin{tabular}{|c|c|c|c|c|c|}
\hline \multirow{3}{*}{$\begin{array}{l}\text { Ingrediente } \\
\text { Ingredient }\end{array}$} & \multicolumn{5}{|c|}{ Nível de lisina (\%) } \\
\hline & \multicolumn{5}{|c|}{ Lysine level } \\
\hline & 0 & 0,5 & 0,10 & 0,15 & 0,20 \\
\hline Farelo de milho grão(Corn meal) & 32,85 & 32,85 & 32,85 & 32,85 & 32,85 \\
\hline Sorgo baixo tanino (Low tanin sorghum) & 31.60 & 31.60 & 31.60 & 31.60 & 31.60 \\
\hline Farelo de soja (Soybean meal) & 17,10 & 17,10 & 17,10 & 17,10 & 17,10 \\
\hline Farelo glúten de milho $60 \%$ (Corn gluten meal) & 2,90 & 2,90 & 2,90 & 2,90 & 2,90 \\
\hline Calcário (Limestone) & 9,40 & 9,40 & 9,40 & 9,40 & 9,40 \\
\hline Óleo vegetal(Vegetable oil) & 1,96 & 1,96 & 1,96 & 1,96 & 1,96 \\
\hline Fosfato bicálcico (Dicalcium phosphate) & 1,48 & 1,48 & 1,48 & 1,48 & 1,48 \\
\hline Amido (Starch) & 1,00 & 0,888 & 0,764 & 0,621 & 0,412 \\
\hline Sal (Salt) & 0,53 & 0,53 & 0,53 & 0,53 & 0,53 \\
\hline Carbonato de potássio (Potassium carbonate) & 0,93 & 0,93 & 0,93 & 0,93 & 0,93 \\
\hline L-Lys HCl & 0,00 & 0,065 & 0,130 & 0,194 & 0,259 \\
\hline DL-Met & 0,07 & 0,117 & 0,163 & 0,209 & 0,255 \\
\hline L-Ile & 0,00 & 0,00 & 0,00 & 0,020 & 0,063 \\
\hline L-Thr & 0,00 & 0,00 & 0,00 & 0,00 & 0,034 \\
\hline L-Trp & 0,00 & 0,00 & 0,013 & 0,026 & 0,039 \\
\hline L-Val & 0,00 & 0,00 & 0,00 & 0,00 & 0,008 \\
\hline Cloreto de colina (60\%) (Choline chloride) & 0,02 & 0,02 & 0,02 & 0,02 & 0,02 \\
\hline Mistura mineral ${ }^{1}$ (Mineral mix) & 0,05 & 0,05 & 0,05 & 0,05 & 0,05 \\
\hline Mistura vitamínica ${ }^{2}$ (Vitamin mix) & 0,10 & 0,10 & 0,10 & 0,10 & 0,10 \\
\hline $\mathrm{BHT}^{3}$ & 0,01 & 0,01 & 0,01 & 0,01 & 0,01 \\
\hline \multirow{2}{*}{\multicolumn{6}{|c|}{$\begin{array}{l}\text { Composição calculada } \\
\text { Calculated composition }\end{array}$}} \\
\hline & & & & & \\
\hline$\overline{\mathrm{PB}(\%)(C P)}$ & 15,00 & 15,073 & 15,172 & 15,271 & 15,395 \\
\hline $\mathrm{EM}(\mathrm{Mcal} / \mathrm{kg})(M E)$ & 2,851 & 2,851 & 2,851 & 2,851 & 2,851 \\
\hline $\mathrm{Ca}(\%)$ & 4,00 & 4,00 & 4,00 & 4,00 & 4,00 \\
\hline $\mathrm{P}$ disponível (\%) (Available P) & 0,357 & 0,357 & 0,357 & 0,357 & 0,357 \\
\hline $\mathrm{Na}(\%)$ & 0,250 & 0,250 & 0,250 & 0,250 & 0,250 \\
\hline $\mathrm{Cl}(\%)$ & 0,191 & 0,191 & 0,191 & 0,191 & 0,191 \\
\hline $\mathrm{K}(\%)$ & 0,537 & 0,537 & 0,537 & 0,537 & 0,537 \\
\hline \multicolumn{6}{|l|}{ Aminoácido digestível (\%) (Digestible amino acid) } \\
\hline Lys & 0,584 & 0,634 & 0,684 & 0,734 & 0,784 \\
\hline Met & 0,310 & 0,354 & 0,399 & 0,444 & 0,489 \\
\hline Met + Cys & 0,526 & 0,571 & 0,616 & 0,661 & 0,706 \\
\hline Thr & 0,502 & 0,502 & 0,502 & 0,502 & 0,533 \\
\hline $\operatorname{Trp}$ & 0,158 & 0,158 & 0,164 & 0,176 & 0,188 \\
\hline Arg & 0,912 & 0,912 & 0,912 & 0,912 & 0,912 \\
\hline His & 0,361 & 0,361 & 0,361 & 0,361 & 0,361 \\
\hline Ile & 0,605 & 0,605 & 0,605 & 0,605 & 0,605 \\
\hline Leu & 1,570 & 1,570 & 1,570 & 1,570 & 1,570 \\
\hline Phe & 0,741 & 0,741 & 0,741 & 0,741 & 0,741 \\
\hline Phe + Tyr & 1,279 & 1,279 & 1,279 & 1,279 & 1,279 \\
\hline Val & 0,661 & 0,661 & 0,661 & 0,661 & 0,668 \\
\hline
\end{tabular}

${ }_{1}^{1}$ Roligomix Aves (Roche) - Composição/kg (Content/kg): Mn- 160 g, Fe-100 g, Zn- 100 g, Cu- 20 g, Co- 2 g, l- 2 g, excipiente q.s.p. (inert) - 1000 g.

${ }^{2}$ Rovimix matrizes (Roche) - Composição/kg (Content/kg): vit. A 12.000 .000 U.I., vit $D_{3} 3.600 .000$ U.I., vit. E 3.500 U. I., vit $B_{1} 2.500 \mathrm{mg}$, vit $B_{2} 8.000 \mathrm{mg}$, vit $B_{6} 3.000 \mathrm{mg}$, ác. pantotênico (pantothenic acid) $12.000 \mathrm{mg}$, biotina (biotin) $200 \mathrm{mg}$, vit. K $3.000 \mathrm{mg}$, ác. fólico (folic acid) $3.500 \mathrm{mg}$, ác. nicotínico (nicotinic acid) $40.000 \mathrm{mg}$, vit. $\mathrm{B}_{12} 20.000 \mathrm{mcg}$, Se $130 \mathrm{mg}$, veículo q.s.p. $1.000 \mathrm{~g}$.

${ }^{3}$ Butil-hidróxi-tolueno (antioxidante).

Massa de ovos: expressa em gramas de ovos por ave por dia (g/ave/dia), multiplicando o peso médio dos ovos no período pelo número total de ovos produzidos no respectivo período, dividido pelo número total de aves dos dias relativos a esse período;

Mudança de peso: todas as poedeiras de cada repetição foram pesadas no início e no final do período experimental, para obtenção do ganho de peso médio, que foi obtido pela diferença entre as duas pesagens;
Qualidade interna do ovo: medida por uma amostra de quatro ovos de cada repetição, coletados nos três últimos dias de cada período experimental de 28 dias. Os ovos, identificados com o número de cada tratamento e repetição, foram coletados e pesados. No mesmo dia, procedeu-se à quebra dos ovos para medição da altura de albúmen e de gema, realizada com micrômetro do tipo AMES S-6428, seguindo-se a metodologia descrita por Snyder (1961), para posterior determinação das unidades Haugh, segundo o 
critério desenvolvido por Haugh (1937). Também foram medidos os diâmetros de albúmen e de gema com paquímetro para determinação dos índices de albúmen e gema.

Os valores das exigências de lisina digestível foram estimados, utilizando as variáveis de desempenho e de qualidade dos ovos, por análises de regressão polinomial, por intermédio do programa SAEG - Sistema para Análises Estatísticas e Genéticas (UFV, 1997). Independentemente de a interação níveis de lisina $\mathrm{x}$ linhagem das aves ter sido significativa ou não, optou-se por seu desdobramento.

\section{Resultados e Discussão}

A mudança de peso e o consumo de ração das poedeiras não foram influenciados pelos níveis de lisina na ração $(\mathrm{P}>0,05)$. As poedeiras leves e semipesadas perderam peso, mas não houve efeito da linhagem sobre a mudança de peso. $\mathrm{O}$ peso inicial médio das aves leves foi de $1,620 \mathrm{~kg}$ e das semipesadas, 1,990 kg (Tabela 2).

O consumo de ração foi influenciado pela linhagem das aves, sendo maior para as aves leves. Todas as aves receberam o mesmo manejo alimentar (ração à vontade), por isso não existe um motivo especial para a linhagem semipesada apresentar menor consumo, contrariando inferências encontradas na literatura de que aves deste tipo geralmente consomem mais que poedeiras leves. Resultados semelhantes aos deste estudo comprovam que os níveis de lisina não afetaram o consumo alimentar (Goulart, 1997).

March \& Biely (1972) relataram que o fato de o aumento de consumo de uma dieta deficiente de lisina falhar em promover aumento do ganho de peso pode decorrer do maior efeito termogênico, em razão do desequilíbrio de aminoácidos e, também, do maior gasto energético para a síntese de proteínas.

Foi verificado efeito quadrático dos níveis de lisina sobre a conversão alimentar ( $\mathrm{kg}$ de ração/dúzia de ovo) das aves em ambas as linhagens comerciais $(\mathrm{P}<0,05)$. Também houve efeito significativo $(\mathrm{P}<0,01)$ da linhagem para a conversão alimentar, de modo que as aves semipesadas obtiveram melhores resultados (1,50 kg de ração/dúzia de ovo) que as leves (1,60 kg de ração/dúzia de ovo). Goulart (1997), trabalhando com seis níveis de lisina $(0,54$ a $0,84 \%)$, também verificou este mesmo efeito na conversão alimentar das aves.

As exigências de lisina foram estimadas em 0,704 e $0,692 \%$, para melhor conversão alimentar, sendo que os consumos diários foram de 859 e $778 \mathrm{mg}$ de lisina/ave, para aves leves e semipesadas, respectivamente (Figura 1; Tabela 3). Bertechini et al. (1995) verificaram que um consumo diário de $789 \mathrm{mg}$ de lisina/ave foi suficiente para boa conversão alimentar (kg de ração/dúzia de ovos). Valores inferiores de consumo de lisina foram sugeridos por Goulart (1997), que determinou maiores valores de exigência, 0,773 e $0,719 \%$ de lisina na ração para poedeiras leves e semipesadas, respectivamente.

Jordão Filho et al. (2003) determinaram as exigências nutricionais de lisina para poedeiras semipesadas utilizando níveis de 0,$64 ; 0,68 ; 0,72 ; 0,76 ; 0,80 ; 0,84$ e $0,88 \%$. Esses autores concluíram que não houve efeito significativo dos níveis de lisina sobre o consumo de ração, a massa de ovos, conversão por massa de ovos e gravidade específica.

Tabela 2 - Efeito dos níveis de lisina digestível sobre o desempenho de poedeiras leves e semipesadas, no período de 34 a 50 semanas de idade

Table 2 - Effect of digestible lysine levels on performance of light and semi-heavy laying hen, in the period from 34 to 50 weeks old

\begin{tabular}{|c|c|c|c|c|c|c|c|c|}
\hline \multirow[t]{2}{*}{$\begin{array}{l}\text { Nível de lisina } \\
\text { Lysine level } \\
(\%)\end{array}$} & \multicolumn{2}{|c|}{$\begin{array}{c}\text { Mudança de peso } \\
\text { (kg/ave) } \\
\text { Weight change } \\
\text { (kg/bird })\end{array}$} & \multicolumn{2}{|c|}{$\begin{array}{l}\text { Consumo de ração } \\
\text { (g/ave.d) } \\
\text { Feed intake } \\
\text { (g/bird.d) }\end{array}$} & \multicolumn{2}{|c|}{$\begin{array}{c}\text { Consumo de lisina }{ }^{\#} \\
\text { (mg/ave.d) } \\
\text { Lysine intake } \\
\text { (mg/bird.d) }\end{array}$} & \multicolumn{2}{|c|}{$\begin{array}{l}\text { Conversão alimentar } \\
\text { (kg ração/dz ovos) } \\
\text { Feed:dozen egg ratio } \\
\text { (kg diet/dozen eggs) }\end{array}$} \\
\hline & $\begin{array}{c}\text { Leve }^{\mathrm{ns}} \\
\text { Light }\end{array}$ & $\begin{array}{l}\text { Semipes. }{ }^{\mathrm{ns}} \\
\text { Semi-heavy }\end{array}$ & $\begin{array}{c}\text { Leve }^{\mathrm{ns}} \\
\text { Light }\end{array}$ & $\begin{array}{l}\text { Semipes. }{ }^{\mathrm{ns}} \\
\text { Semi-heavy }\end{array}$ & $\begin{array}{l}\text { Leve } \\
\text { Light }\end{array}$ & $\begin{array}{l}\text { Semipes. } \\
\text { Semi-heavy }\end{array}$ & $\begin{array}{c}\text { Leve }^{2} \\
\text { Light }\end{array}$ & $\begin{array}{l}\text { Semipes. } \\
\text { Semi-heavy }\end{array}$ \\
\hline 0,584 & $-0,300$ & $-1,258$ & 124,6 & 110,4 & 727,6 & 644,7 & 1,69 & 1,52 \\
\hline 0,684 & $-0,033$ & $-0,433$ & 121,0 & 110,8 & 827,6 & 757,9 & 1,56 & 1,46 \\
\hline 0,734 & $-0,147$ & $-0,020$ & 122,9 & 114,8 & 902,0 & 842,6 & 1,59 & 1,50 \\
\hline 0,784 & $-0,222$ & $-0,395$ & 121,4 & 113,0 & 951,8 & 885,9 & 1,60 & 1,51 \\
\hline Média ${ }^{1}$ & $-0,204 a$ & $-0,530 a$ & $122,0 \mathrm{a}$ & $112,5 \mathrm{a}$ & 834,1 & 770,3 & $1,60 \mathrm{a}$ & $1,50 \mathrm{~b}$ \\
\hline CV (\%) & \multicolumn{2}{|c|}{4,65} & \multicolumn{2}{|c|}{3,71} & & & \multicolumn{2}{|c|}{4,66} \\
\hline
\end{tabular}

1 Médias seguidas de letras diferentes na linha para cada variável diferem pelo teste $F(P<0,01)$, representando efeito da linhagem nas variáveis em estudo.

2 Efeito quadrático significativo dos níveis de lisina pelo teste $F(P<0,05)$.

ns Não-significativo para os níveis de lisina $(P>0,05)$.

\# Efeito não incluído nas análises estatísticas (nível de lisina $x$ comsumo de ração).

Means followed by different letters within a row for each variable differ $(P<0.01)$ by $F$ test, representing effect of strain in the studied variable.

2 Significant quadratic effect of lysine levels by $F$ test.

ns Not significant $(P<0.05)$ effect of lysine levels.

\# Effect not included in the statistical analyses (lysine level $x$ feed intake). 
Tabela 3 - Estimativas da exigência de lisina digestível (\%) para poedeiras leves e semipesadas no período de 34 a 50 semanas de idade, considerando a mudança de peso, o consumo de ração e a conversão alimentar, ajustados por modelos de regressão

Table 3 - Estimates of digestible lysine requirement (\%) for light and semi-heavy laying hens in the period from 34 to 50 weeks old, considering weight change, feed intake and feed:egg dozen ratio, fitted by regression equations

\begin{tabular}{lcrc}
\hline Item & $\begin{array}{l}\text { Regressão } \\
\text { Regression }\end{array}$ & Pmáx/Pmín & $\begin{array}{c}\text { Exigência lisina } \\
\text { Lysine requirement }\end{array}$ \\
\hline Conversão alimentar (Feed:egg dozen ratio) & $\hat{\mathrm{Y}}=5,67165-11,6749 \mathrm{x}+8,28571 \mathrm{x}^{2}$ & 1,56 & 0,704 \\
Conversão alimentar (Feed:egg dozen ratio) & $\hat{\mathrm{Y}}=3,26022-5,14114 \mathrm{x}+3,71429 \mathrm{x}^{2}$ & 1,48 & $0,89^{*}$ \\
\hline
\end{tabular}

${ }^{* *}(P<0,01),{ }^{*}(P<0,05)$ pelo teste $F$.

Pmáx (Ponto de máxima) (Maximal value) e Pmín (Ponto de mínima) (Minimal value).

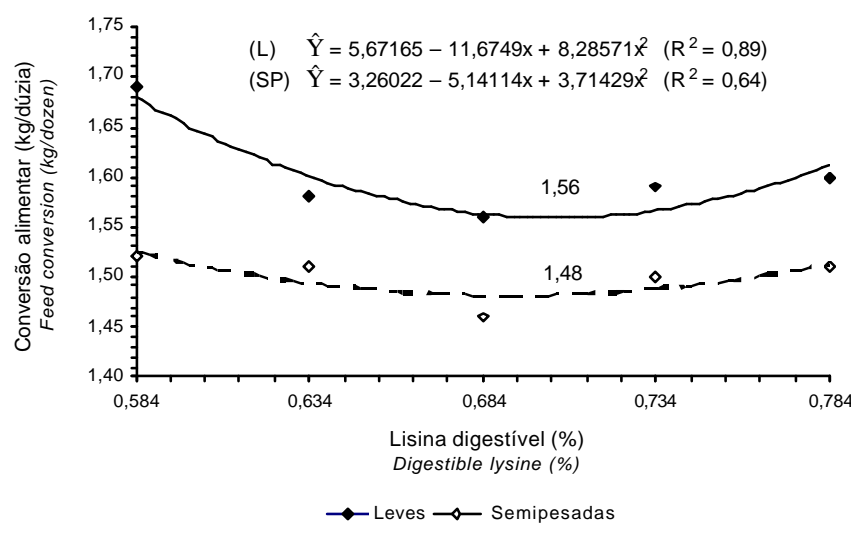

Figura 1 - Efeito dos níveis de lisina digestível na ração sobre a conversão alimentar (kg ração/dúzia ovos) de poedeiras leves (L) e semipesadas (SP), no período de 34 a 50 semanas de idade.

Figure 1 - Effect of the dietary digestible lysine levels on feed:egg dozen ratio ( $\mathrm{kg}$ diet/egg dozen) of light $(L)$ and semi-heavy $\mathrm{(SH)}$ laying hens, in the period from 34 to 50 weeks old.

Entretanto, houve efeito sobre a produção de ovos e a conversão por dúzia de ovos para exigências estimadas em 0,766 e $0,753 \%$, respectivamente, recomendando-se exigência de $0,76 \%$ ou $822 \mathrm{mg}$ de lisina/ave/dia. Esses resultados corroboram os obtidos por Silva et al. (2002), que determinaram requerimento de lisina de $0,77 \%$, que equivale ao consumo de $839 \mathrm{mg}$ de lisina/ave/dia.

Houve efeito significativo $(\mathrm{P}<0,01)$ da linhagem sobre a produção dos ovos e o peso médio dos ovos. As aves leves tiveram maior produção de ovos que as semipesadas $(90,68$ e $89,27 \%)$, todavia, as aves semipesadas apresentaram ovos mais pesados $(62,66 \mathrm{~g})$ que as leves $(60,92 \mathrm{~g})$, o que foi suficiente para que não fossem verificadas diferenças entre as linhagens para massa de ovos (Tabela 4).

A produção, o peso e a massa dos ovos foram influenciados pelos níveis de lisina na ração tanto para as aves leves como para as semipesadas. Foi verificado efeito quadrático $(\mathrm{P}<0,01)$ dos níveis de lisina sobre a produção e a massa de ovos (Tabela 5; Figura 2) e efeito linear $(\mathrm{P}<0,01)$ sobre o peso dos ovos. As exigências de lisina foram estimadas em 0,706 e 0,732\%, equivalendo ao consumo médio diário de 861 e $893 \mathrm{mg}$ de lisina/ave para a produção e massa de ovos, respectivamente, para as aves leves. Para as aves semipesadas, os requerimentos de lisina determinados foram de 0,714 e $0,715 \%$, correspondendo a um consumo médio diário de 803 e $804 \mathrm{mg}$ de lisina/ave para a produção e massa de ovos, respectivamente.

Apesar de a variável peso de ovo ter apresentado efeito linear, não foi feita a recomendação da exigência de lisina com base neste parâmetro, visto que o aumento do peso do ovo por si só não é importante, mas sim a produção e a massa de ovos (Tabela 5; Figura 2).

Houve efeito significativo $(\mathrm{P}<0,01)$ da linhagem sobre a unidade Haugh, de modo que as aves leves apresentaram valor médio dos ovos maior que as semipesadas. O índice de albúmen também apresentou efeito significativo $(\mathrm{P}<0,01)$ em função da marca comercial, observando-se que as aves leves tiveram maior valor médio de ovos que as semipesadas. Por outro lado, o índice de gema não diferiu ( $\mathrm{P}>0,01)$ entre as linhagens, sendo que os valores médios foram semelhantes entre as mesmas (Tabela 6).

Não foi observado efeito significativo $(\mathrm{P}>0,05)$ dos diferentes níveis de lisina sobre as variáveis unidade Haugh e índices de gema e albúmen dos ovos, tanto das poedeiras leves como das semipesadas, durante o período experimental (Tabela 6). A unidade Haugh, o índice de gema e o índice de albúmen tiveram médias nos tratamentos de 96,12; 0,443 e 0,133 e de 90,$65 ; 0,444$ e 0,115 , respectivamente, para as aves leves e semipesadas. Goulart (1997), trabalhando com níveis de 0,50 a $0,80 \%$ de lisina na ração, verificou efeito linear dos níveis de lisina sobre o índice de gema e a unidade Haugh, enquanto para índice de albúmen foi verificado efeito quadrático para as poedeiras leves.

À semelhança do resultado obtido neste experimento, Jardim Filho et al. (2004) verificaram que o peso do ovo foi influenciado de forma negativa com o aumento da suplementação de lisina; porém, o percentual de albúmen e de gema, a unidade Haugh, o índice de gema e os sólidos totais não foram afetados pelos níveis de lisina estudados. 
Tabela 4 - Efeito dos níveis lisina digestível sobre a produção de ovos, peso médio dos ovos e massa de ovos de galinhas poedeiras leves e semipesadas, no período de 34 a 50 semanas de idade

Table 4 - Effect of digestible lysine levels on egg production, average egg weight and egg mass of light and semi-heavy laying hens, in the period from 34 to 50 weeks old

\begin{tabular}{|c|c|c|c|c|c|c|}
\hline \multirow[t]{2}{*}{$\begin{array}{l}\text { Nível de lisina (\%) } \\
\text { Lysine level }\end{array}$} & \multicolumn{2}{|c|}{$\begin{array}{l}\text { Produção de ovos }(\%) \\
\text { Egg production }(\%)\end{array}$} & \multicolumn{2}{|c|}{$\begin{array}{c}\text { Peso médio dos ovos }(\mathrm{g}) \\
\text { Average egg weight }\end{array}$} & \multicolumn{2}{|c|}{$\begin{array}{c}\text { Massa de ovos (g/ave.d) } \\
\text { Egg mass(g/bird.d) }\end{array}$} \\
\hline & $\begin{array}{l}\text { Leve }^{3} \\
\text { Light }\end{array}$ & $\begin{array}{l}\text { Semipesada }^{3} \\
\text { Semi-heavy }\end{array}$ & $\begin{array}{r}\text { Leve }^{2} \\
\text { Light }\end{array}$ & $\begin{array}{l}\text { Semipesada } \\
\text { Semi-heavy }\end{array}$ & $\begin{array}{r}\text { Leve }^{3} \\
\text { Light }\end{array}$ & $\begin{array}{l}\text { Semipesada } \\
\text { Semi-heavy }\end{array}$ \\
\hline 0,584 & 87,54 & 86,21 & 59,05 & 61,45 & 51,60 & 52,98 \\
\hline 0,634 & 90,85 & 89,38 & 59,57 & 61,56 & 54,10 & 55,03 \\
\hline 0,684 & 92,37 & 90,47 & 61,67 & 62,70 & 56,98 & 56,74 \\
\hline 0,734 & 92,07 & 90,65 & 61,68 & 63,58 & 56,76 & 57,69 \\
\hline 0,784 & 90,58 & 89,63 & 62,63 & 64,00 & 56,01 & 57,40 \\
\hline Média $^{1}$ & $90,68 \mathrm{a}$ & $89,27 b$ & $60,92 b$ & $62,66 \mathrm{a}$ & $55,09 \mathrm{a}$ & $55,97 \mathrm{~b}$ \\
\hline Mean & & & & & & \\
\hline CV (\%) & 2,48 & 2,11 & 3,11 & & & \\
\hline
\end{tabular}

${ }^{1}$ Médias seguidas de letras diferentes na linha para cada variável diferem entre si pelo teste $F(P<0,01)$, representando efeito da linhagem nas variáveis em estudo.

2 Efeito linear significativo dos níveis de lisina pelo teste $F(P<0,01)$.

${ }^{3}$ Efeito quadrático significativo dos níveis de lisina pelo teste $F(P<0,01)$.

${ }_{1}^{1}$ Means followed by different letters within a row for each variable differ $(P<0.01)$ by $F$ test, representing effect of strain in the studied variable.

2 Significant linear effect $(P<0.01)$ of lysine levels by $F$ test.

${ }^{3}$ Significant quadratic effect $(P<0.01)$ of lysine levels by $F$ test.

Tabela 5 - Estimativas da exigência de lisina digestível (\%) para poedeiras leves e semipesadas no período de 34 a 50 semanas de idade, considerando a produção de ovos, o peso de ovos, a massa de ovos, a unidade Haugh e os índices de gema e de albúmen, ajustadas por modelos de regressão

Table 5 - Estimates of digestible lysine requirement (\%) for light and semi-heavy laying hens in the period from 34 to 50 weeks old, considering egg production, egg weight, egg mass, Haugh unit and yolk and albumen indices, fitted by regression equations

\begin{tabular}{|c|c|c|c|c|}
\hline Item & $\begin{array}{l}\text { Regressão } \\
\text { Regression }\end{array}$ & Pmáx/Pmín & $\begin{array}{l}\text { Exigência lisina } \\
\text { Lysine requirement }\end{array}$ & $\mathrm{R}^{2}$ \\
\hline Produção de ovos (Egg production) & $\hat{Y}=-70,3277+460,959 x-326,286 x^{2}$ & 92,48 & 0,706 & $0,99 *$ \\
\hline Massa de ovos (Egg mass) & $\hat{Y}=-31,705+235,630 x-155,430 x^{2}$ & 57,49 & 0,732 & $0,99 *$ \\
\hline Produção de ovos (Egg production) & $\hat{Y}=-44,6817+379,326 x-265,429 x^{2}$ & 90,84 & 0,714 & $0,99 * *$ \\
\hline Massa de ovos (Egg mass) & $\hat{Y}=-87,569+398,180 x-274,290 x^{2}$ & 56,84 & 0,715 & $0,99 *$ \\
\hline
\end{tabular}

${ }^{* *}(P \leq 0,01),{ }^{*}(P \leq 0,05)$ pelo teste $F$.

Pmáx (Ponto de máxima) (Maximal value) e Pmín (Ponto de mínima) (Minimal value).

(a)

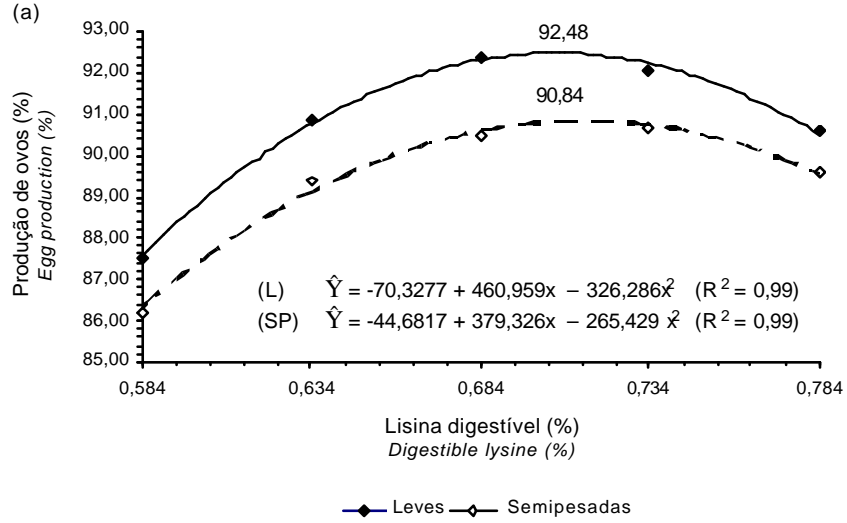

(b)

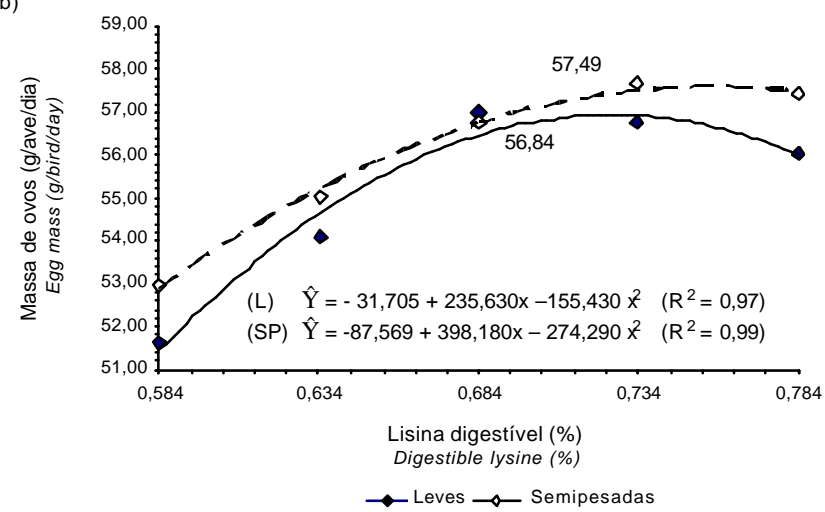

Figura 2 - Efeito dos níveis de lisina digestível na ração sobre a produção de ovos (\%) (a) e a massa de ovos (g/ave/dia) (b) de poedeiras leves (L) e semipesadas (SP), no período de 34 a 50 semanas de idade.

Figure 2 - Effect of the dietary digestible lysine levels on egg production (\%) (a) and egg mass ( $\mathrm{g} /$ bird/day) (b) of light and semi-heavy laying hens, in the period from 34 to 50 weeks old. 
Berterchini et al. (1995) observaram que o aumento na suplementação de lisina na dieta das poedeiras comerciais não incrementou os valores de unidade Haugh dos ovos. Contudo, Novack et al. (2000) obtiveram melhores resultados de peso de ovo, percentual de gema e albúmen, ao utilizarem o nível de $0,90 \%$ de lisina na ração.

Prochaska et al. (1996) concluíram que níveis crescentes de lisina na ração (638 para $1063 \mathrm{mg} / \mathrm{ave} / \mathrm{dia}$ ) melhoraram as características de peso da gema e integridade das membranas internas do ovo, resultando em ovos com maior conteúdo de sólidos totais e melhor qualidade interna. Avaliando quatro níveis de inclusão de lisina na dieta de poedeiras variando de 0,60 a $0,90 \%$, Silva et al. (2004) não observaram efeito de tratamento sobre o peso do ovo, percentual de albúmen e gema, a unidade Haugh, o índice de gema e os sólidos totais, concordando com os resultados encontrados neste ensaio.

$\mathrm{O}$ requerimento de lisina digestível oscilou entre 0,704 e $0,732 \%$, correspondendo ao consumo diário de 859 e $893 \mathrm{mg}$ de lisina/ave, para as aves leves (Tabela 7). Para as poedeiras semipesadas, a exigência de lisina digestível variou entre 0,692 e $0,715 \%$, equivalente ao consumo de 778 e $804 \mathrm{mg}$ de lisina/ave/dia. Tendo em vista os resultados obtidos, foi estabelecido como exigência de lisina digestível para poedeiras leves o nível de $0,732 \%$ ou o consumo diário de $893 \mathrm{mg}$ de lisina/ave e para poedeiras

Tabela 6 - Efeito dos níveis de lisina digestível sobre a unidade Haugh e os índices de gema e de albúmen de ovos de poedeiras leves e semipesadas, no período de 34 a 50 semanas de idade

Table 6 - Effect of digestible lysine levels on Haugh unit and egg albumen and yolk index of light and semi-heavy laying hens in the period from 34 to 50 weeks old

\begin{tabular}{|c|c|c|c|c|c|c|}
\hline \multirow[t]{2}{*}{$\begin{array}{l}\text { Nível de lisina (\%) } \\
\text { Lysine level }\end{array}$} & \multicolumn{2}{|c|}{$\begin{array}{l}\text { Unidade Haugh } \\
\text { Haugh unit }\end{array}$} & \multicolumn{2}{|c|}{$\begin{array}{l}\text { Índice de gema } \\
\text { Egg yolk index }\end{array}$} & \multicolumn{2}{|c|}{$\begin{array}{l}\text { Índice de albúmen } \\
\text { Albumen index }\end{array}$} \\
\hline & $\begin{array}{l}\text { Leve }^{\mathrm{ns}} \\
\text { Light }\end{array}$ & $\begin{array}{l}\text { Semipesada }{ }^{\mathrm{ns}} \\
\text { Semi-heavy }\end{array}$ & $\begin{array}{l}\text { Leve }^{\mathrm{ns}} \\
\text { Light }\end{array}$ & $\begin{array}{c}\text { Semipesada }{ }^{\mathrm{ns}} \\
\text { Semi-heavy }\end{array}$ & $\begin{array}{l}\text { Leve }^{\mathrm{ns}} \\
\text { Light }\end{array}$ & $\begin{array}{l}\text { Semipesada }{ }^{\mathrm{ns}} \\
\text { Semi-heavy }\end{array}$ \\
\hline 0,584 & 95,49 & 90,51 & 0,442 & 0,446 & 0,133 & 0,114 \\
\hline 0,634 & 96,10 & 90,51 & 0,445 & 0,447 & 0,133 & 0,114 \\
\hline 0,684 & 96,89 & 92,04 & 0,443 & 0,450 & 0,136 & 0,119 \\
\hline 0,734 & 96,13 & 90,73 & 0,442 & 0,440 & 0,131 & 0,115 \\
\hline 0,784 & 96,00 & 89,44 & 0,442 & 0,439 & 0,133 & 0,112 \\
\hline Média $^{1}$ & $96,12 \mathrm{a}$ & $90,65 b$ & $0,443 \mathrm{a}$ & $0,444 b$ & $0,133 \mathrm{a}$ & $0,115 b$ \\
\hline $\begin{array}{l}\text { Mean } \\
\text { CV }(\%)\end{array}$ & \multicolumn{2}{|c|}{2,15} & \multicolumn{2}{|c|}{3,32} & \multicolumn{2}{|c|}{5,49} \\
\hline
\end{tabular}

1 Médias seguidas de letras diferentes na linha para cada variável diferem entre si pelo teste $F(P<0,01)$, representando efeito da linhagem nas variáveis em estudo.

ns Não-significativo para os níveis de lisina $(P>0,05)$.

1 Means followed by different letters within a row for each variable differ $(P<0.01)$ by $F$ test, representing effect of the strain in the studied variable.

ns Not significant effect $(P>0.05)$ of lysine levels.

Tabela 7 - Exigências nutricionais de lisina digestível (\%, mg/dia) para conversão alimentar, produção de ovos e massa de ovos para poedeiras leves e semipesadas no período de 34 a 50 semanas de idade

Table 7 - Digestible lysine requirements (\%, $\mathrm{mg} /$ day) for feed:egg dozen ratio, egg production and egg mass of light and semi-heavy laying hens in the period from 34 to 50 weeks old

\begin{tabular}{|c|c|c|c|c|}
\hline \multirow[t]{2}{*}{ Item } & \multicolumn{2}{|c|}{$\begin{array}{l}\text { Leves } \\
\text { Light }\end{array}$} & \multicolumn{2}{|c|}{$\begin{array}{l}\text { Semipesadas } \\
\text { Semi-heavy }\end{array}$} \\
\hline & $\begin{array}{c}\text { Lisina digestível } \\
\text { Digestible lysine }\end{array}$ & $\begin{array}{l}\text { Mglisina/d } \\
\text { mg lysine/d }\end{array}$ & $\begin{array}{c}\text { Lisina digestível } \\
\text { Digestible lysine }\end{array}$ & $\begin{array}{c}\mathrm{mg} \text { lisina/d } \\
\text { mg lysine/d }\end{array}$ \\
\hline Conversão alimentar (kg/dz) (Feed:egg dozen ratio) & 0,704 & 859 & 0,692 & 778 \\
\hline Produção de ovos (\%) (Egg production) & 0,706 & 861 & 0,714 & 803 \\
\hline Massa de ovos (kg/ave.d) (Egg mass, kg/bird.d) & 0,732 & 893 & 0,715 & 804 \\
\hline
\end{tabular}


semipesadas, o nível de $0,715 \%$ de lisina digestível ou o consumo de $893 \mathrm{mg}$ de lisina/ave/dia, uma vez que atendem às exigências determinadas para todas as características estudadas.

\section{Conclusões}

As exigências estimadas de lisina digestível foram de 0,732 e $0,715 \%$ para poedeiras leves e semipesadas, respectivamente, correspondendo a consumos diários de 893 e $804 \mathrm{mg}$ de lisina para poedeiras leves e semipesadas, respectivamente.

\section{Literatura Citada}

BERTECHINI, A.G.; TEIXEIRA A.S.; LIRA, V.M.C. Níveis de lisina para poedeiras comerciais leves na fase de pico de postura. In: CONFERÊNCIA APINCO DE CIÊNCIA E TECNOLOGIA AVÍCOLA, 1995, Curitiba. Anais... Curitiba: Fundação APINCO de Ciência e Tecnologia Avícolas, 1995. p.75.

CHUNG, T.K.; BAKER, D.H. Ideal amino acid pattern for $10-$ kilogram pigs. Journal of Animal Science, v.70, p.3102$3111,1992$.

COON, C.; ZHANG, B. Ideal amino acid profile for layers examined. Feedstuffs, v.71, n.14, p.13-15, 1999.

GOULART, C.C. Exigência nutricional de lisina para poedeiras leves e semipesadas. Viçosa, MG: Universidade Federal de Viçosa, 1997. 51p. Dissertação (Mestrado em Zootecnia) - Universidade Federal de Viçosa, 1997.

HAUGH, R.R. The Haugh unit for measuring egg quality. U.S. Egg and Poultry Management, v.4, p.552, 1937.

HSU, J.C.; LIN, C.Y.; CHIOU, P.W. Effects of ambient temperature and methionine supplementation of a low protein diet on the performance of laying hens. Animal Feed Science and Technology, v.74, p.289-299, 1998.

JARDIM FILHO, R.M.; SANTOS, G.P.; STRINGHINI, J.H. et al. Características internas de ovos de poedeiras comerciais Lohmann alimentadas com níveis crescentes de lisina digestível. In: CONFERÊNCIA APINCO DE CIÊNCIA E TECNOLOGIA AVÍCOLAS, 2004, Santos. Trabalhos de Pesquisa... Santos: Fundação APINCO de Ciência e Tecnologia Avícolas, 2004. p. 103 .

JORDÃO FILHO, J.; SILVA, J.H.V.; SILVA, E.L. et al. Exigências nutricionais de lisina para poedeiras semipesadas. In: CONFERÊNCIA APINCO DE CIÊNCIA E TECNOLOGIA AVÍCOLAS, 2003, Santos. Trabalhos de Pesquisa... Santos: Fundação APINCO de Ciência e Tecnologia Avícolas, 2003. p.61.
MARCH, B.E.; BIELY, J. The effects of protein level and amino acid balance in wheat-based laying rations. Poultry Science, v. 51, n.1, p.547-570, 1972 .

NOVACK, C.; YAKOUT, H.; SCHEIDELER, S. Lysine levels in laying hens diets. The Nebraska Poultry Report, v.72, p.21$23,2000$.

PROCHASKA, J.F.; CAREY, J.B.; SHAFER, D.J. The effect of L-lysine intake on egg component yield and composition in laying hens. Poultry Science, v.75, p.1268-1077, 1996.

RIZZO, M.F.; FARIA, D.E.; ROMBOLA, L.G. et al. Avaliação das propriedades funcionais de ovos produzidos por poedeiras alimentadas com diferentes níveis de lisina e metionina. In CONFERÊNCIA APINCO DE CIÊNCIA E TECNOLOGIA AVÍCOLAS, 2004, Santos. Trabalhos de Pesquisa... Santos: Associação Brasileira dos Produtores de Pintos de Corte, 2004. p.41.

ROSTAGNO, H.S.; ALBINO, L.F.T.; DONZELE, J.L. et al.Tabelas brasileiras para aves e suínos: composição de alimentos e exigências nutricionais. Viçosa, MG: Universidade Federal de Viçosa, 2000. 141p.

SCHUTTE, J.B.; JONG, J. [2004]. Ideal amino acid profile for poultry. Disponível em: <http://www.resources.chiem.org/om/ pdf/c37/99600024.pdf> Acesso em: 10/11/2004.

SILVA, T.R.; JARDIM FILHO, R.M.; STRINGHINI, J.H. et al. Influência dos níveis de lisina sobre as características internas de ovos de poedeiras comerciais Hy Line W 36. In: CONFERÊNCIA APINCO DE CIÊNCIA E TECNOLOGIA AVÍCOLAS, 2004, Santos. Trabalhos de Pesquisa... Santos: Associação Brasileira dos Produtores de Pintos de Corte, 2004. p.106.

SNYDER, E.S. Eggs, the production, the identification and retention of quality in eggs. Guelph: Ontario Agricultural College, 1961. 90p.

UNIVERSIDADE FEDERAL DE VIÇOSA - UFV.SAEG - Sistema para Análises Estatísticas e Genéticas. versão 7.0 Viçosa, MG: 1997. 59p.

SILVA, J.H.V.; JORDÃO FILHO, J.; SILVA, E.L. et al. Exigência de metionina de poedeiras semipesadas mantendo ou não a relação aminoácidos sulfurosos:lisina. In: CONFERÊNCIA APINCO DE CIÊNCIA E TECNOLOGIA AVÍCOLAS, 2002, Santos. Trabalhos de Pesquisa... Santos: Associação Brasileira dos Produtores de Pintos de Corte, 2002. p.69. 